\title{
Genetic diversity in the germplasm of tropical maize landraces determined using molecular markers
}

\author{
D. Molin ${ }^{1}$, C.J. Coelho ${ }^{2}$, D.S. Máximo ${ }^{2}$, F.S. Ferreira ${ }^{2}$, J.R. Gardingo ${ }^{3}$ and \\ R.R. Matiello ${ }^{1,2,3}$ \\ ${ }^{1}$ Pós-Graduação em Ciências Biológicas, Biologia Evolutiva, \\ Ponta Grossa, PR, Brasil \\ ${ }^{2}$ Pós-Graduação em Agronomia, Agricultura, Ponta Grossa, PR, Brasil \\ ${ }^{3}$ Departamento de Fitotecnia e Fitossanidade, \\ Setor de Ciências Agrárias e de Tecnologia, \\ Universidade Estadual de Ponta Grossa, Ponta Grossa, PR, Brasil \\ Corresponding author: R.R. Matiello \\ E-mail: rrmatiel@uepg.br \\ Genet. Mol. Res. 12 (1): 99-114 (2013) \\ Received August 6, 2012 \\ Accepted November 19, 2012 \\ Published January 22, 2013 \\ DOI http://dx.doi.org/10.4238/2013.January.22.8
}

\begin{abstract}
Maize landraces derived from tropical germplasm represent an important source of genetic variability, which is currently poorly understood and under-exploited by Brazilian crop breeding programs. The aims of our study were to a) estimate the genetic diversity across 48 varieties of maize landraces cultivated at different locations in the States of Rio Grande do Sul (RS) and Paraná (PR) by means of random amplified polymorphic DNA (RAPD), simple sequence repeat (SSR), and amplified fragment length polymorphism (AFLP) markers; b) cluster these varieties based on their genetic similarity estimates, and c) establish possible correlations between genetic similarity and germplasm collection sites. Maize landrace accessions were genotyped through the 30 RAPD, 47 SSR, and 25 combinations of AFLP primers. The results revealed high levels of variability across landraces within and between collection sites. AFLP analysis resulted in amplification
\end{abstract}


of 762 polymorphic fragments and a polymorphic index of $40.3 \%$, followed by RAPD with 335 fragments $(81.9 \%)$ and SSR with 105 fragments (78.3\%). The genetic similarity estimates of the investigated landraces ranged from 41 (SSR) to $74 \%$ (AFLP), and the amplitudes of these indices were notably similar between RAPD and SSR, as well as between AFLP and joint analysis. Regarding the RAPD and AFLP dendrograms, groups comprising accessions from RS prevailed, whereas SSR comprised varieties from both collection sites. Groups exclusive to RS or PR support the hypothesis that divergence between groups is possible owing to the fixation of regional adaptation alleles and to spatial barriers hindering genetic flow between locations.

Key words: Molecular polymorphism; Genetic similarity; Clustering; Variability

\section{INTRODUCTION}

Maize germplasm includes landraces, adapted populations, and introduced exotic materials. Landraces are important genotypes for crop breeding owing to their high potential to adapt to specific environmental conditions and the large source of genetic variability that they provide (Paterniani et al., 2000). Landraces are generally less productive than commercial cultivars, although in recent years, they have become important as sources of genetic variability in the search for genes for tolerance or resistance to biotic and abiotic factors of interest in agriculture (Araújo and Nass, 2002).

The genetic diversity observed across landraces is the most important part of maize biodiversity, and local races represent an important fraction of the genetic variability exhibited by this genus. However, few agronomic and genetic data exist for such collections, and this scarcity has limited the use, management, and conservation of this germplasm. In addition, a few improved genotypes with narrower genetic variability are quickly replacing maize landraces (Pollack, 2003).

Molecular characterization is frequently used by maize breeders as an alternative method for selecting more promising genotypes and reducing the cost and time needed to develop hybrid combinations. According to Garcia et al. (2004), tropical maize populations that originate from hybridizations exhibit high genetic variability compared with that of temperate populations, and allocating tropical compounds to well-defined heterotic groups based solely on phenotypic assessment is usually difficult. However, molecular characterization is efficient for determining the genetic diversity of maize and the composition of such groups.

Studies of genetic diversity across individuals have been stimulated by the amplification of DNA sequences using polymerase chain reaction (PCR) (Saiki et al., 1988). Several methods have been applied in this regard: random amplified polymorphic DNA (RAPD) (Williams et al., 1990), simple sequence repeat (SSR) (Tautz, 1989), and amplified fragment length polymorphism (AFLP) (Zabeau and Vos, 1993). RAPD is widely used in studies of maize diversity owing to its low cost and rapid detection of polymorphisms (Carvalho et al., 2004; Bruel et al., 2007). SSR features high reproducibility, accuracy, and discrimination. Owing to their specificity and ease of detection, SSRs are one of the main markers used to characterize the genetic resources of plants via the genotyping of germplasm collections and 
analysis of genetic diversity (Adeyemo et al., 2011; Terra et al., 2011). AFLP is a nearly ideal system because it allows the assessment of genetic diversity across individuals, populations, and species (Laborda et al., 2005; Hartings et al., 2008). This technique reveals a large portion of the genome of any organism and allows for high-resolution and high-quality genotyping. According to Gerber et al. (2000), the loss of information owing to the expression of the dominant marker is counterbalanced by the high number of polymorphic loci revealed by this method. The aims of the present study were to estimate the genetic diversity across 48 varieties of maize landraces from southern Brazil by means of molecular genotyping using RAPD, SSR, and AFLP markers, cluster these landrace varieties based on their index of genetic similarity, and establish possible correlations with the collection sites.

\section{MATERIAL AND METHODS}

\section{Plant material and molecular analysis}

Forty-eight varieties of maize landraces were used for molecular analysis, of which 18 originated in the State of Paraná (PR) and 30 from Rio Grande do Sul (RS; Table 1). The genomic DNA of each variety was extracted from a sample of young leaves collected from 15 plants per variety. The hexadecyltrimethylammonium bromide method described by Hoisington et al. (1994) was used for extraction.

Table 1. List of maize landrace varieties used in molecular analysis and the corresponding collection sites.

\begin{tabular}{rlllll}
\hline Treat & Landraces & Collection site/State & Treat & Landraces & Collection site/State \\
\hline 1 & Nutricional & Rio Azul/PR & 25 & Crioulo Riscado & Veranópolis/RS \\
2 & Milho Grande & Ponta Grossa/PR & 26 & Dente de Ouro 2 & Pelotas/RS \\
3 & Palha Roxa & Rio Azul/PR & 27 & Crioulo Amarelão & Veranópolis/RS \\
4 & Paiol & Ponta Grossa/PR & 28 & População Nonoai & Nonoai/RS \\
5 & Branco & Rio Azul/PR & 29 & Pintadinho FE 109 & Canela/RS \\
6 & Asteca & Rio Azul/PR & 30 & Crioulo Veranópolis & Veranópolis/RS \\
7 & Caiano & Rio Azul/PR & 31 & Crioulo 8 Carreiras & Veranópolis/RS \\
8 & Roxo Índio I & Canguçu/RS & 32 & Crioulo Cunha Roxo & Veranópolis/RS \\
9 & Branco p/ Palha & Rio Azul/PR & 33 & BR 451 & Pelotas/RS \\
10 & Pérola & Rio Azul/PR & 34 & Crioulo Rosa & Veranópolis/RS \\
11 & Carioca & Rio Azul/PR & 35 & Colonial & Pelotas/RS \\
12 & Astequinha Sab. Fino & Rio Azul/PR & 36 & Catete Amarelo & Canguçu/RS \\
13 & Vinten & Rio Azul/PR & 37 & Caiano FE 121 & Tenente Portela/RS \\
14 & Palha Roxa & Rio Azul/PR & 38 & Branco Dentado & Canguçu/RS \\
15 & Encantilado & Rio Azul/PR & 39 & Branco FE 126 & Candiota/RS \\
16 & Branco & Rio Azul/PR & 40 & Argentino FE 128 & Alto União/RS \\
17 & Amarelo Antigo & Rio Azul/PR & 41 & Caiano & Ponta Grossa/PR \\
18 & Crioulo 8 Carreiras & Veranópolis/RS & 42 & Branco & Ponta Grossa/PR \\
19 & Crioulo Pururuca & Veranópolis/RS & 43 & Cinquentinha & Ibarama/RS \\
20 & Caiano Rajado & Canguçu/RS & 44 & Roxo Índio II & Canguçu/RS \\
21 & Vermelhão FE 127 & Candiota/RS & 45 & Dente de Ouro & Canguçu/RS \\
22 & Cunha & Ibarama/RS & 46 & Argentino Flint & Canguç/RS \\
23 & Crioulo Sabugo Fino & Veranópolis/RS & 47 & Crioulo Branco Comum & Veranópolis/RS \\
24 & Crioulo Asteca & Veranópolis/RS & 48 & Crioulo Palha Roxa & Veranópolis/RS \\
\hline PR $=$ Paraná RS = Rio Grande do Sul & & &
\end{tabular}

\section{RAPD markers}

Thirty RAPD primers (Operon Technologies Inc., Alameda, CA, USA) were subjected 
to temperature gradient testing during the PCR annealing step to ensure a robust amplification of fragments. The amplification reactions were prepared in a $20-\mu \mathrm{L}$ volume containing $1 \mathrm{X}$ Green Go Taq ${ }^{\circledR}$ Flexi buffer, $4.0 \mathrm{mM} \mathrm{MgCl}, 0.27 \mathrm{mM}$ of each deoxyribonucleotide triphosphate (Amresco, Solon, OH, USA), $0.8 \mu \mathrm{M}$ of each primer, $1.0 \mathrm{U}$ Taq DNA polymerase (Promega, Madison, WI, USA), and $40 \mathrm{ng}$ template DNA. The reaction comprised 1 cycle of initial denaturation for $3 \mathrm{~min}$ at $94^{\circ} \mathrm{C}$, followed by 45 cycles of denaturation at $94^{\circ} \mathrm{C}$ for $1 \mathrm{~min}$, a specific annealing temperature for each primer for $45 \mathrm{~s}$, and elongation at $72^{\circ} \mathrm{C}$ for $2 \mathrm{~min}$, and a final extension at $72^{\circ} \mathrm{C}$ for $6 \mathrm{~min}$.

\section{SSR markers}

Forty-seven pairs of microsatellite primers (forward and reverse) were used, representing the 10 linkage groups of the maize consensus map. On average, 4.7 primers were analyzed per linkage group with amplitudes between 4 and 7 primers. PCRs were prepared in a $20-\mu \mathrm{L}$ volume containing $1 \mathrm{X}$ Green Go Taq ${ }^{\circledR}$ Flexi buffer, $2.0 \mathrm{mM} \mathrm{MgCl}, 0.1 \mathrm{mM}$ of each deoxyribonucleotide triphosphate, $0.2 \mu \mathrm{M}$ primer (forward and reverse), $0.75 \mathrm{U}$ Taq DNA polymerase (Promega), and $40 \mathrm{ng}$ template DNA. The amplification reactions were based on the protocols of Senior et al. (1996), Ogliari et al. (2000), and Yao et al. (2007).

The fragments amplified using RAPD and SSR were stained with GelRed 0.1X (Biotium, Hayward, CA, USA) and loading buffer ( $0.25 \%$ bromophenol blue and $0.4 \%$ sucrose $)$ at a 1:1 ratio. The PCR products were separated on 2 and $3 \%$ agarose gels, respectively, for approximately $4 \mathrm{~h}$ at $80 \mathrm{~V}$ in $1 \mathrm{X}$ Tris-borate ethylenediaminetetraacetic acid buffer. Five microliters of 100-bp marker (Norgen Biotek, Toronto, Canada) was added to the far left lane. The gels were photodocumented under ultraviolet light on an MF-ChemisBis device (DNR Bio-Imaging Systems Ltd., Jerusalem, Israel).

\section{AFLP marker}

The landrace varieties were genotyped with 25 combinations of EcoRI $+M s e I$ primers according to Vos et al. (1995). Briefly, the genomic DNA of each sample was doubly digested using the EcoRI (Promega) and MseI (Invitrogen, USA) restriction enzymes. Then, restriction enzyme adaptors were ligated onto the digested fragments. Pre-amplification was performed using the $E c o \mathrm{RI}+\mathrm{A}$ and $M s e \mathrm{I}+\mathrm{C}$ primers in the $3^{\prime}$ position, and selective amplification was performed using primers containing 3 selective nucleotides in the 3 ' position. The products of selective amplification were denatured and separated on $6 \%$ polyacrylamide gels. Electrophoresis was performed in $1 \mathrm{X}$ Tris-borate ethylenediaminetetraacetic acid buffer at $80 \mathrm{~W}$ for 3.5 h (Sequi-Gen GT Nucleic Acid Electrophoresis Cell/BIORAD Apparatus of Electrophoresis, Hercules, CA, USA). Silver ion impregnation was performed according to the method described by Creste et al. (2001).

\section{Data analysis}

The fragments produced by the genotyping of landrace varieties were entered in a binary data matrix ( 1 and 0 ). Only polymorphic fragments were subjected to analysis of genetic similarity using the Jaccard coefficient. Clustering analysis was based on the similarity 
matrix of the investigated landrace varieties, and we used the unweighted pair-group arithmetic method. Similarity and clustering analyses were performed separately and jointly for all 3 types of markers using NTSYS pc 2.1 (Rohlf, 1992) and GENES version 7.0 (Cruz, 2006). The correlation between the individual and joint genetic similarity matrices was investigated using the Mantel test (Mantel, 1967) with NTSYS pc 2.1 (Rohlf, 1992).

\section{RESULTS}

\section{Molecular polymorphisms}

Thirty RAPD primers amplified 409 fragments corresponding to an average of 13.6 fragments per primer and measuring approximately 160 to $2000 \mathrm{bp}$. From these fragments, $335(81.9 \%)$ were polymorphic and $74(18.1 \%)$ were monomorphic. The lowest percentage of polymorphisms was detected in OPAR-02 $(30 \%)$ and the highest $(100 \%)$ was found in OPAW08, OPY-04, OPAX-10, OPAW-11, OPAT-08, and OPAR-16 (Table 2).

Table 2. List of RAPD primers, total number of amplified fragments, number of monomorphic fragments, number of polymorphic fragments, rate of polymorphism, and the number of polymorphic fragments per primer.

\begin{tabular}{|c|c|c|c|c|c|}
\hline Primer & Sequence & Fragments & Monomorphic & Polymorphic & Polymorphism (\%) \\
\hline 1) OPAR-04 & 5'-CCAGGAGAAG-3' & 5 & 1 & 4 & 80.0 \\
\hline 2) OPAW-10 & 5'-GTTGTTTGCC-3' & 18 & 3 & 15 & 83.3 \\
\hline 3) OPAV-13 & 5'-CTGACTTCCC-3' & 11 & 2 & 9 & 81.8 \\
\hline 4) OPAW-19 & 5'-GGACACAGAG-3' & 13 & 4 & 9 & 69.2 \\
\hline 5) OPAV-19 & 5'-CTCGATCACC-3' & 14 & 3 & 11 & 78.6 \\
\hline 6) OPAW-08 & 5'-CTGTCTGTGG-3' & 8 & 0 & 8 & 100.0 \\
\hline 7) OPAR-05 & 5'-CATACCTGCC-3' & 12 & 4 & 8 & 66.7 \\
\hline 8) OPAW-14 & 5'-GGTTCTGCTC-3' & 18 & 3 & 15 & 83.3 \\
\hline 9) OPW-08 & 5'-GACTGCCTCT-3' & 15 & 6 & 9 & 60.0 \\
\hline 10) OPAU-12 & 5'-CCACTGGTCT-3' & 17 & 3 & 14 & 82.6 \\
\hline 11) OPY-10 & 5'-CAAACGTGGG-3' & 21 & 2 & 19 & 90.5 \\
\hline 12) OPAD-14 & 5'-GAACGAGGGT-3' & 16 & 2 & 14 & 87.5 \\
\hline 13) OPW-09 & 5'-GTGACCGAGT-3' & 13 & 5 & 8 & 61.5 \\
\hline 14) OPAM-01 & 5'-TCACGTACGG-3' & 8 & 4 & 4 & 50.0 \\
\hline 15) OPAR-02 & 5'-CACCTGCTGA-3' & 10 & 7 & 3 & 30.0 \\
\hline 16) OPAR-15 & 5'-ACACTCTGCC-3' & 14 & 4 & 10 & 71.4 \\
\hline 17) OPY-04 & 5'-GGCTGCAATG-3' & 18 & 0 & 18 & 100.0 \\
\hline 18) OPE-18 & 5'-CGACTGCAGA-3' & 10 & 4 & 6 & 60.0 \\
\hline 19) OPAV-03 & 5'-TGTAGCCGTG-3' & 9 & 2 & 7 & 77.8 \\
\hline 20) OPW-13 & 5'-CACAGCGACA-3' & 20 & 2 & 18 & 90.0 \\
\hline 21) OPP-05 & 5'-CCCCGGTAAC-3' & 13 & 3 & 10 & 76.9 \\
\hline 22) OPAD-06 & 5'-AAGTGCACGG-3' & 13 & 1 & 12 & 92.3 \\
\hline 23) OPAX-10 & 5'-CCAGGCTGAC-3' & 13 & 0 & 13 & 100.0 \\
\hline 24) OPAW-11 & 5'-CTGCCACGAG-3' & 17 & 0 & 17 & 100.0 \\
\hline 25) OPAT-08 & 5'-TCCTCGTGGG-3' & 12 & 0 & 12 & 100.0 \\
\hline 26) OPAX-07 & 5'-ACGCGACAGA-3' & 15 & 3 & 12 & 80.0 \\
\hline 27) OPAK-15 & 5'-ACCTGCCGTT-3' & 12 & 3 & 9 & 75.0 \\
\hline 28) OPAW-07 & 5'-AGCCCCCAAG-3' & 17 & 2 & 15 & 88.2 \\
\hline 29) OPAR-16 & 5'-CCTTGCGCCT-3' & 14 & 0 & 14 & 100.0 \\
\hline 30) OPY-09 & 5'-AGCAGCGCAC-3' & 13 & 1 & 12 & 92.3 \\
\hline Total & & 409 & 74 & 335 & 81.9 \\
\hline
\end{tabular}

Genotyping with the 47 SSR primers amplified 134 fragments measuring approximately 100 to $400 \mathrm{bp}$. From these fragments, 105 (78.3\%) were polymorphic and $29(21.7 \%)$ were monomorphic. The number of fragments per primer ranged from 1 to 7 , with an average of 2.9. 
Among the informative primers, 26 displayed $100 \%$ polymorphism, and the remainder ranged from 33.3 (Umc 1463) to 66.7\% (Phi 034, Umc 1519, and Bnlg 640), as shown in Table 3.

\begin{tabular}{|c|c|c|c|c|c|c|c|}
\hline No. & Primer & Group/bin & $\begin{array}{l}\text { Repetitive } \\
\text { motives }\end{array}$ & Fragments & Monomorphic & Polymorphic & Polymorphism (\%) \\
\hline 1 & Bnlg 149 & $1 / 00$ & Indeterminate & 2 & 0 & 2 & 100 \\
\hline 2 & Bnlg 1007 & $1 / 02$ & $(\mathrm{AG})_{15}$ & 3 & 0 & 3 & 100 \\
\hline 3 & Umc 1035 & $1 / 06$ & $(\mathrm{CT})_{19}^{13}$ & 1 & 1 & 0 & 0 \\
\hline 4 & Bnlg 131 & $1 / 11$ & Indeterminate & 5 & 0 & 5 & 100 \\
\hline 5 & Bnlg 125 & $2 / 02$ & Indeterminate & 3 & 0 & 3 & 100 \\
\hline 6 & Umc 1884 & $2 / 05$ & $(\mathrm{TC})_{8}$ & 5 & 0 & 5 & 100 \\
\hline 7 & Bnlg 1045 & $2 / 07$ & $(\mathrm{AG})_{17}$ & 5 & 0 & 5 & 100 \\
\hline 8 & Phi 101049 & $2 / 10$ & (AGAT) & 3 & 0 & 3 & 100 \\
\hline 9 & Umc 2118 & $3 / 00$ & $(\mathrm{CTTT})_{4}$ & 3 & 0 & 3 & 100 \\
\hline 10 & Umc 1223 & $3 / 04$ & $(\mathrm{AG})_{7}$ & 3 & 0 & 3 & 100 \\
\hline 11 & Bnlg 197 & $3 / 06$ & Indeterminate & 2 & 1 & 1 & 50 \\
\hline 12 & Umc 1136 & $3 / 10$ & $(\mathrm{GCA})_{5}$ & 2 & 0 & 2 & 100 \\
\hline 13 & Umc 1759 & $4 / 01$ & $(\mathrm{CGG})_{4}^{5}$ & 7 & 4 & 3 & 42.8 \\
\hline 14 & Umc 2176 & $4 / 03$ & $(\mathrm{TGC})_{4}^{4}$ & 3 & 0 & 3 & 100 \\
\hline 15 & Bnlg 490 & $4 / 04$ & Indeterminate & 2 & 0 & 2 & 100 \\
\hline 16 & Bnlg 2291 & $4 / 06$ & $(\mathrm{AG})_{17}$ & 3 & 0 & 3 & 100 \\
\hline 17 & Bnlg 1784 & $4 / 07$ & $(\mathrm{AG})_{13}^{17}$ & 1 & 1 & 0 & 0 \\
\hline 18 & Bnlg 1565 & $4 / 09$ & $(\mathrm{AG})_{27}$ & 5 & 0 & 5 & 100 \\
\hline 19 & Bnlg 1337 & $4 / 11$ & $(\mathrm{AG})_{21}$ & 6 & 0 & 6 & 100 \\
\hline 20 & Umc 2036 & $5 / 01$ & $(\mathrm{GTC})_{4}$ & 1 & 1 & 0 & 0 \\
\hline 21 & Bnlg 557 & $5 / 03$ & Indeterminate & 2 & 1 & 1 & 50 \\
\hline 22 & Umc 1348 & $5 / 05$ & $(\mathrm{CA})_{7}$ & 2 & 1 & 1 & 50 \\
\hline 23 & Umc 1792 & $5 / 08$ & $(\mathrm{CGG})_{5}$ & 1 & 1 & 0 & 0 \\
\hline 24 & Umc1829 & $5 / 09$ & $(\mathrm{AG})_{10}$ & 4 & 0 & 4 & 100 \\
\hline 25 & Bnlg $249^{a}$ & $6 / 01$ & Indeterminate & 3 & 0 & 3 & 100 \\
\hline 26 & Phi 077 & $6 / 01$ & $(\mathrm{AG})$ & 2 & 0 & 2 & 100 \\
\hline 27 & Umc 1887 & $6 / 04$ & $(\mathrm{CGA})_{4}$ & 2 & 1 & 1 & 50 \\
\hline 28 & Phi 452693 & $6 / 04$ & (AGCC) & 2 & 0 & 2 & 100 \\
\hline 29 & Umc 1463 & $6 / 06$ & $(\mathrm{ACA})_{6}$ & 3 & 2 & 1 & 33.3 \\
\hline 30 & Bnlg 1292 & $7 / 01$ & $(\mathrm{AG})_{14}$ & 4 & 0 & 4 & 100 \\
\hline 31 & Phi 034 & $7 / 02$ & $(\mathrm{CCT})$ & 3 & 1 & 2 & 66.7 \\
\hline 32 & Bnlg 434 & $7 / 03$ & Indeterminate & 3 & 0 & 3 & 100 \\
\hline 33 & Phi 082 & $7 / 05$ & $(\mathrm{AG})$ & 1 & 1 & 0 & 0 \\
\hline 34 & Umc 1799 & $7 / 06$ & $(\mathrm{TG})_{12}$ & 5 & 0 & 5 & 100 \\
\hline 35 & Umc 1592 & $8 / 01$ & $(\mathrm{CA})^{12}$ & 2 & 2 & 0 & 0 \\
\hline 36 & Phi 115 & $8 / 03$ & (AT/ATAC) & 2 & 0 & 2 & 100 \\
\hline 37 & Bnlg 240 & $8 / 06$ & Indeterminate & 2 & 0 & 2 & 100 \\
\hline 38 & Phi 015 & $8 / 08$ & $(\mathrm{AAAC})$ & 4 & 2 & 2 & 50 \\
\hline 39 & Phi 233376 & $8 / 09$ & (CCG) & 1 & 1 & 0 & 0 \\
\hline 40 & Umc 2084 & $9 / 01$ & $(\mathrm{CTAG})_{4}$ & 3 & 0 & 3 & 100 \\
\hline 41 & Phi 065 & $9 / 03$ & (CACTT) & 2 & 1 & 1 & 50 \\
\hline 42 & Phi 027 & $9 / 03$ & (GCGCT) & 2 & 0 & 2 & 100 \\
\hline 43 & Umc 1519 & $9 / 04$ & $(\mathrm{TC})_{8}$ & 3 & 1 & 2 & 66.7 \\
\hline 44 & Umc 1319 & $10 / 01$ & $(\mathrm{ACC})_{5}$ & 2 & 1 & 1 & 50 \\
\hline 45 & Bnlg 640 & $10 / 03$ & Indeterminate & 3 & 1 & 2 & 66.7 \\
\hline 46 & Bnlg 1250 & $10 / 05$ & $(\mathrm{AG})_{30}$ & 4 & 2 & 2 & 50 \\
\hline 47 & Umc 2021 & $10 / 07$ & $(\mathrm{TGG})_{4}$ & 2 & 2 & 0 & 0 \\
\hline Total & & & & 134 & 29 & 105 & 78.3 \\
\hline Polymorphic fragments/primer & & & & & & 2.2 & \\
\hline
\end{tabular}

Twenty-five combinations of EcoRI and MseI primers produced 1889 fragments measuring approximately 47 to $1153 \mathrm{bp}$. The average number of fragments per primer was 75.6, with amplitudes ranging from 42 (E-ATC/M-CGC) to 106 (E-ACA/M-CAT). Of these fragments, 1127 (59.7\%) were monomorphic, and 762 (40.3\%) were polymorphic. In 13 combinations, the polymorphic index was $<40 \%$; the indexes of 5 combinations were $>52.7 \%$, particularly in E-ACA/M-CGC (67.8\%) and E-AGT/M-CGC (65.5\%; Table 4). From the markers 
used in genotyping of landrace varieties, AFLP amplified an average of 30.5 polymorphic fragments per primer, which was 3- and 14-fold higher than the rate of polymorphism detected with RAPD and SSR markers, respectively (see Tables 2 and 4).

\begin{tabular}{|c|c|c|c|c|c|}
\hline No. & Primers & Fragments & Monomorphic & Polymorphic & Polymorphism (\%) \\
\hline 1 & E-AGC/M-CCA & 64 & 30 & 34 & 53.1 \\
\hline 2 & E-ATC/M-CCA & 90 & 50 & 40 & 44.4 \\
\hline 3 & E-AGC/M-CAC & 68 & 37 & 31 & 45.6 \\
\hline 4 & E-ACA/M-CAC & 81 & 57 & 24 & 29.6 \\
\hline 5 & E-ATC/M-CAC & 89 & 59 & 30 & 33.7 \\
\hline 6 & E-ACA/M-CCA & 93 & 58 & 35 & 37.6 \\
\hline 7 & E-AAC/M-CAC & 82 & 38 & 44 & 53.7 \\
\hline 8 & E-AGT/M-CAC & 92 & 60 & 32 & 34.8 \\
\hline 9 & E-AAC/M-CAC & 88 & 45 & 43 & 48.9 \\
\hline 10 & E-AGT/M-CCA & 55 & 40 & 15 & 27.3 \\
\hline 11 & E-AGT/M-CGC & 58 & 20 & 38 & 65.5 \\
\hline 12 & E-ATC/M-CGC & 42 & 26 & 16 & 38.1 \\
\hline 13 & E-AGC/M-CGC & 73 & 41 & 32 & 43.8 \\
\hline 14 & E-ACA/M-CGC & 59 & 19 & 40 & 67.8 \\
\hline 15 & E-AAC/M-CGC & 55 & 26 & 29 & 52.7 \\
\hline 16 & E-AGT/M-CTC & 66 & 38 & 28 & 42.4 \\
\hline 17 & E-AGC/M-CTC & 72 & 47 & 25 & 34.7 \\
\hline 18 & E-ATC/M-CTC & 60 & 48 & 12 & 20.0 \\
\hline 19 & E-ACA/M-CTC & 77 & 50 & 27 & 35.1 \\
\hline 20 & E-AAC/M-CTC & 91 & 60 & 31 & 34.1 \\
\hline 21 & E-AGT/M-CAT & 67 & 50 & 17 & 25.4 \\
\hline 22 & E-ATC/M-CAT & 84 & 60 & 24 & 28.6 \\
\hline 23 & E-AGC/M-CAT & 98 & 57 & 41 & 41.8 \\
\hline 24 & E-ACA/M-CAT & 106 & 63 & 43 & 40.6 \\
\hline 25 & E-AAC/M-CAT & 79 & 48 & 31 & 39.2 \\
\hline Total & & 1889 & 1127 & 762 & 40.3 \\
\hline Polymorphic fragments/primer & & & & 30.5 & \\
\hline
\end{tabular}

\section{Genetic similarity}

The genetic similarity estimates revealed an average index of $57 \%$ with RAPD markers with amplitudes between 46 and 70\%. População Nonoai (V8) compared to Dente de Ouro (V45), Crioulo Rosa (V34), and Crioulo Palha Roxa (V48) exhibited the lowest genetic similarity, whereas comparisons of Asteca (V6) and Caiano (V7) exhibited the highest similarity. The average similarity estimate with the SSR markers was 56\%; the comparison between Branco (V42) and Crioulo Palha Roxa (V48) exhibited the highest divergence, with an index of $41 \%$, whereas maximal similarity $(76 \%)$ was observed in the comparison between Nutricional (V1) and Branco para Palha (V9; Table 5).

The similarity values for AFLP and joint analyses of markers were highly similar; coefficients ranged from 59 to $89 \%$ for the former and 58 to $81 \%$ for the latter, with averages of 74 and 69\%, respectively. The Branco (V16) and Branco Dentado (V38) varieties generally exhibited the least similarity among all combinations (AFLP and joint analysis). In addition, the Branco (V16) variety combined with População Nonoai (V28) and Crioulo 8 Carreiras (V31) exhibited the lowest index in joint analysis. In contrast, the combination between Branco (V16) and Carioca (V11) exhibited the highest genetic similarity among all varieties in both AFLP (89\%) and joint (81\%) analyses (Table 5). 
Table 5. Minimum and maximum values, amplitude, and mean of genetic similarity obtained with RAPD, SSR, and AFLP markers and joint analysis.

\begin{tabular}{|c|c|c|c|c|c|c|}
\hline Marker & Minimum & Varieties & Maximum & Varieties & Amplitude & Mean \\
\hline RAPD & 0.46 & $\begin{array}{l}\mathrm{V} 28 \text { and V45 } \\
\mathrm{V} 28 \text { and V34 } \\
\mathrm{V} 28 \text { and V48 }\end{array}$ & 0.70 & $\mathrm{~V} 6$ and $\mathrm{V} 7$ & 0.24 & 0.57 \\
\hline SSR & 0.41 & V42 and V48 & 0.76 & V1 and V9 & 0.35 & 0.56 \\
\hline AFLP & 0.59 & $\begin{array}{l}\mathrm{V} 16 \text { and V38 } \\
\mathrm{V} 16 \text { and V38 }\end{array}$ & 0.89 & V6 and V11 & 0.30 & 0.74 \\
\hline Joint & 0.58 & $\begin{array}{l}\mathrm{V} 16 \text { and V28 } \\
\mathrm{V} 16 \text { and V31 }\end{array}$ & 0.81 & V6 and V11 & 0.23 & 0.69 \\
\hline
\end{tabular}

\section{Clustering of landrace varieties}

The RAPD and SSR dendrograms revealed that the 48 maize landrace varieties formed 8 heterotic groups. However, 6 varieties (V27, V32, V16, V31, V34, and V28) did not cluster with RAPD, and only Pérola (V10) remained isolated with SSR (Figures 1 and 2).

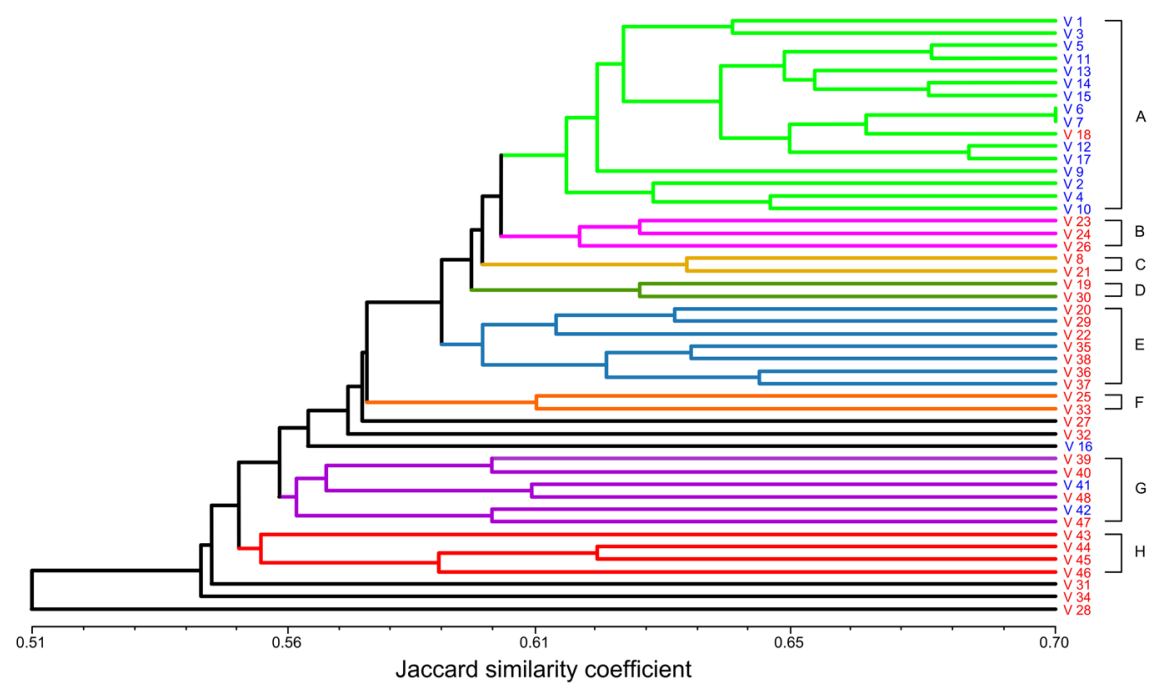

Figure 1. Dendrogram generated from the genetic similarity across the 48 maize landrace varieties (V1-V48) using the RAPD markers. Numbers of varieties in blue indicate genotypes from Paraná, and in red correspond to Rio Grande do Sul. Different branch colors represent the 8 different groups (A-H) formed based on the Jaccard similarity index by means of UPGMA.

Clustering with AFLP exhibited remarkable contrasts between markers in terms of the number of groups and isolated varieties in the dendrograms. Our analysis revealed the formation of only 6 heterotic groups comprising 27 landrace varieties and a significant percentage (44\%) of varieties that remained isolated (Figure 3). On joint analysis, the topology of the tree was similar to that of the AFLP tree. The varieties that remained isolated with AFLP formed heterotic group $\mathrm{G}$; the other changes in clustering concerned the inclusion or exclusion of varieties in groups B, $\mathrm{C}$, and E. Heterotic groups D and F maintained the same number of genotypes, although their composition was entirely different than that observed with AFLP analysis (Figure 4). 


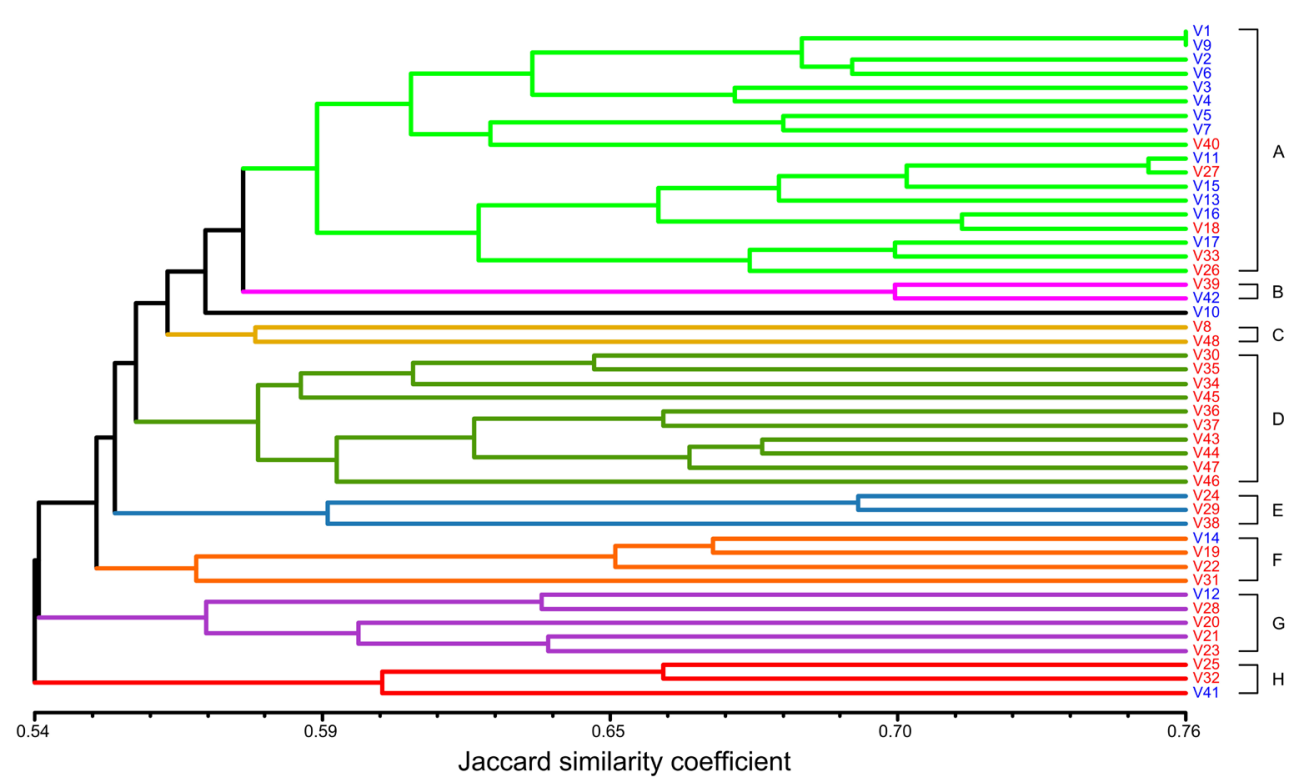

Figure 2. Dendrogram generated from the genetic similarity across the 48 maize landrace varieties using the SSR markers. Numbers of varieties in blue indicate genotypes from Paraná, and in red correspond to Rio Grande do Sul. Different branch colors represent the 8 different groups $(\mathrm{A}-\mathrm{H})$ formed based on the Jaccard similarity index by means of UPGMA.

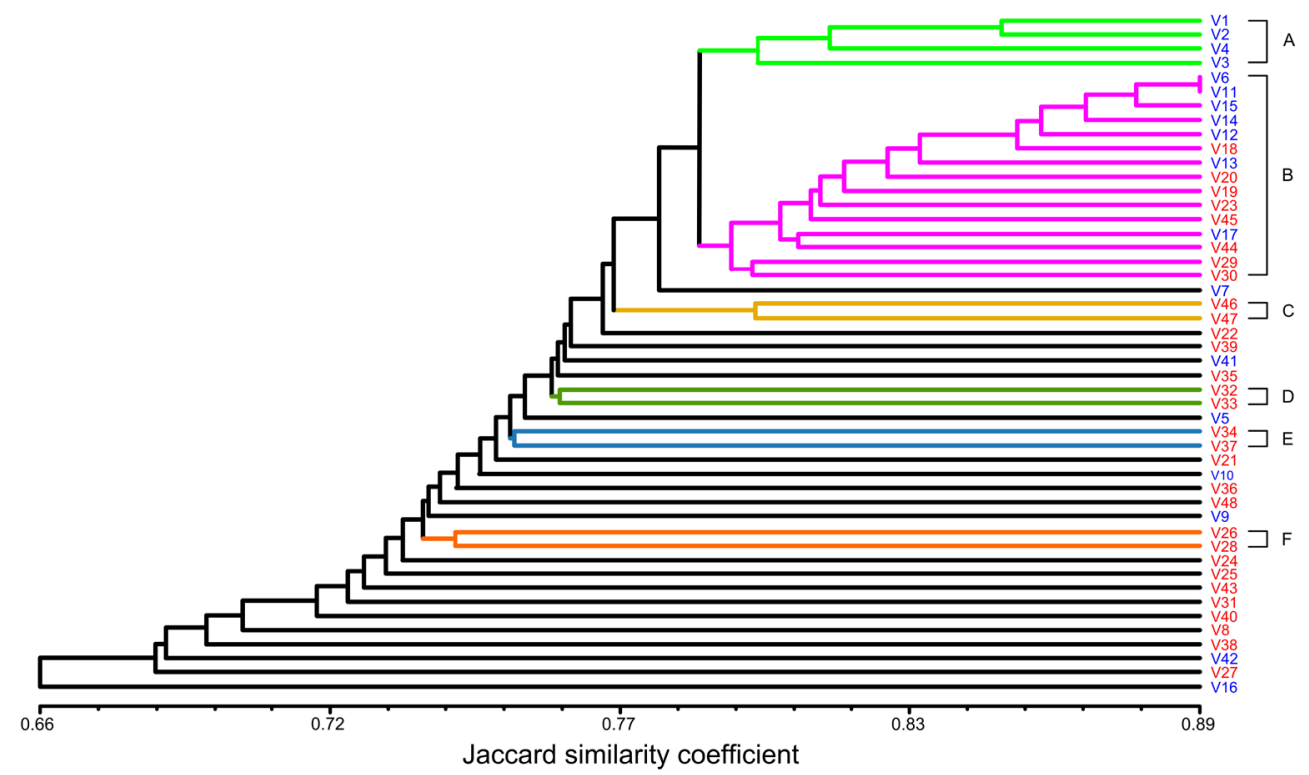

Figure 3. Dendrogram generated from the genetic similarity across the 48 maize landrace varieties using the AFLP markers. Numbers of varieties in blue indicate genotypes from Paraná, and in red correspond to Rio Grande do Sul. Different branch colors represent the 6 different groups (A-F) formed based on the Jaccard similarity index by means of UPGMA. 


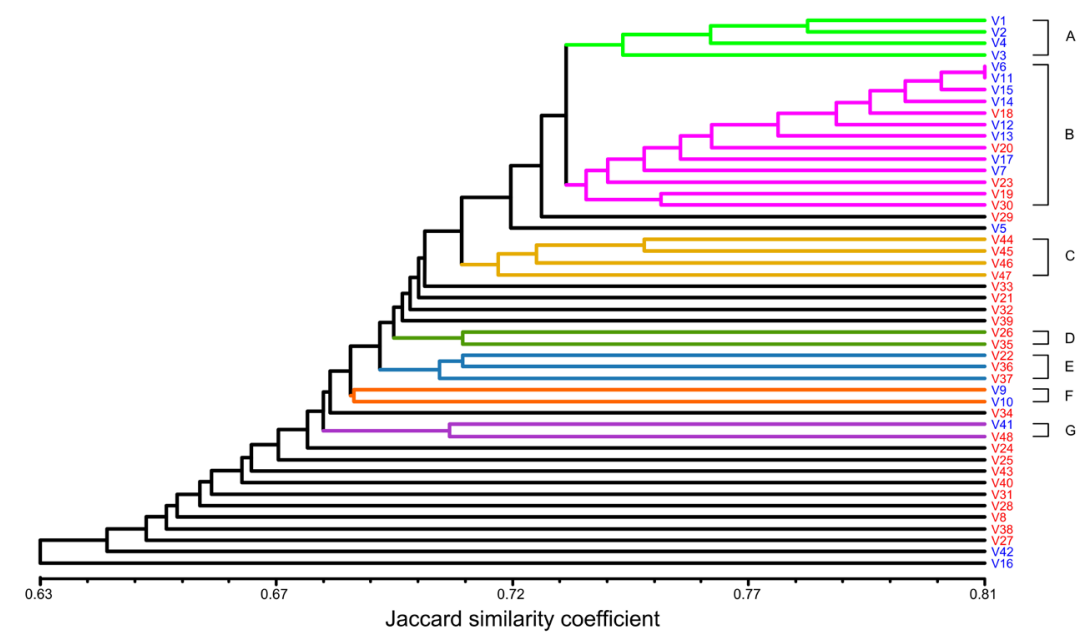

Figure 4. Dendrogram generated from the genetic similarity across the 48 maize landrace varieties using the RAPD, SSR, and AFLP markers. Numbers of varieties in blue indicate genotypes from Paraná, and in red correspond to Rio Grande do Sul. Different branch colors represent the 7 different groups (A-G) formed based on the Jaccard similarity index by means of UPGMA.

Correlation analysis between genetic similarity matrices allowed us to determine the associations between the similarity indices as well as to confirm the results obtained through cluster analysis of the landraces. The highest correlation was found between AFLP and joint analysis (96\%) followed by RAPD and joint analysis (66\%). Intermediate values (46 and 44\%) were found in the associations RAPD/AFLP and SSR/joint analysis, respectively. The lower values were estimated for RAPD/SSR and SSR/AFLP, with only 31 and 30\%, respectively.

\section{DISCUSSION}

The number of fragments amplified using RAPD primers was higher than that found by Carvalho et al. (2004), who assessed 81 maize landraces using 32 primers, and that of Garcia et al. (2004) and Lanza et al. (1997), who studied genetic divergence across 18 inbred maize lines. However, the rate of polymorphisms found in the present study was similar to that observed by Bruel et al. (2007) and Lanza et al. (1997). Carvalho et al. (2004), Moeller and Schaal (1999), and Rinaldi et al. (2007) have obtained lower polymorphic indices ranging from 71 to $76 \%$. The number of polymorphic fragments per primer (11.2) found in the present study agreed with the findings of Moeller and Schaal (1999), although lower rates have also been reported (Lanza et al., 1997; Carvalho et al., 2004; Rinaldi et al., 2007). These differences in the number of fragments and polymorphic rates may be associated with the genetic background of the genotypes or alterations needed to adjust the methods applied by different laboratories when using this marker.

Genotyping with the SSR markers identified 134 fragments with an average of 2.9 fragments per marker, a result identical to those of Garcia et al. (2004) and Barbosa et al. (2003), who found the same number of alleles per locus in maize inbred lines using 68 primers. Xiang et al. (2010) have investigated diversity across maize landrace varieties using 41 primers and found 
an average of 6.9 alleles per locus, as did Yao et al. (2007). Notably different results have been reported by Yang et al. (2011) in a study in which 82 primers produced an average of 8.2 alleles per locus, and by Eschholz et al. (2008), who obtained an average of 10.8 alleles per locus with just 10 primers in Swiss flint maize germplasm. The rate of polymorphisms found in the present study was similar to that reported by Xiang et al. (2010) and much lower than the $97 \%$ observed by Yao et al. (2007). In regard to the number of polymorphic fragments per primer, the value in the present study (2.2) was lower than that described by Adeyemo et al. (2011).

These differences in the number of fragments and the rate of polymorphisms compared with those in the literature may be associated with the type of matrix (agarose or polyacrylamide) used to separate the fragments. This possibility is highlighted in the studies of Yao et al. (2007) and Xiang et al. (2010), in which a higher number of alleles per locus with SSR analysis was reported using polyacrylamide gels. In addition, Kostova et al. (2006) have observed that the use of SSRs with dinucleotide repeats might result in a greater number of alleles, which is in agreement with Yang et al. (2011) and Eschholz et al. (2008), who used 44 and 50\% of primers to sample these regions, respectively. In the present study, only $38 \%$ of the SSR primers sampled repetitive dinucleotides, which may be reflected in the lower number of amplified fragments per locus.

The results obtained with AFLP markers were much higher than those reported in the literature, which range from 278 to 638 fragments when using an average of 8 primer combinations (Laborda et al., 2005; Hartings et al., 2008; Legesse et al., 2008). The results reported by Barbosa et al. (2003) and Garcia et al. (2004) were the closest to those of the present study with respect to the number of primers analyzed (20 combinations), although their number of amplified fragments was lower. The rate of polymorphism (40.3\%) found in the present study was also much lower than that reported by several authors - e.g., Barbosa et al. (2003) and Legesse et al. (2008). The number of polymorphic fragments per primer (30.5) agreed with the results of Hartings et al. (2008) and Barbosa et al. (2003), although higher rates have been reported (Laborda et al., 2005; Legesse et al., 2008). These differences may be due to the number of primer combinations used and the lack of prior selection for the best combinations. In other words, all available combinations were used to genotype the full set of landrace varieties. According to Caixeta et al. (2009), the combination of restriction enzymes might affect the number of polymorphic loci produced.

Analysis of the polymorphic index associated with each marker revealed that SSR and RAPD techniques exhibited the highest indices ( 78.3 and $74.1 \%$, respectively), which agreed with the results of Caixeta et al. (2009), who observed that the level of polymorphisms detected using AFLP is lower compared with that of other markers such as SSR. However, assessment of the efficiency of the various markers in the production of polymorphisms revealed that AFLP were superior, with an average of 30.5 polymorphic fragments per primer. This finding corresponds to a 3-fold greater relative efficiency compared with that of RAPD and a 14-fold improvement over SSR markers, agreeing with results reported by Caixeta et al. (2009) and Gerber et al. (2000), who observed that a smaller number of AFLP primer combinations are sufficient to produce an appropriate number of polymorphic fragments.

Further issues worth considering are the number of accessions investigated, the genetic background of the germplasm (temperate or tropical), and especially, the genomic region sampled by each marker. In general, a higher number of investigated accessions and more varied genetic background result in a higher expected polymorphic rate. Differences inherent in the markers must also be taken into account. For instance, RAPD techniques use short 
primers (10 nucleotides) with random sequences, whereas SSR methods use specific primers (20 to $25 \mathrm{bp}$ ) for the regions flanking microsatellites. AFLP techniques combine the specificity of restriction enzymes with the exponential amplification of PCR. The diversity index estimates confirmed the wide genetic variability of landrace varieties. The estimated amplitudes of genetic diversity for the full set of investigated varieties were 30 to $54 \%$ using RAPD and 24 to $59 \%$ with SSR methods; these values supported the initial hypothesis of high genetic variability among these accessions of maize landraces.

The low genetic diversity among accessions of maize obtained with the AFLP method compared with those obtained with RAPD and SSR techniques may be associated with the fact that the EcoRI and MseI restriction sites are located in highly conserved regions of the genomes of these maize varieties. According to Vuylsteke et al. (1999), who investigated the distribution of AFLP fragments in the maize genome by means of various combinations of restriction enzymes exhibiting different levels of methylation, the clustering of fragments largely co-localizes in the centromeric regions of chromosomes, primarily when such combinations as $E c o \mathrm{RI} / M s e \mathrm{I}$ and ${ }^{\mathrm{m}} P s t \mathrm{I} / M s e \mathrm{I}$ are used, whereas $P s t \mathrm{I} / M s e \mathrm{I}$ produces fragments more randomly spread across the genome. However, the vast majority of studies in the literature have used EcoRI/MseI to amplify fragments with AFLP. In addition, according to Jansen et al. (1996), EcoRI/MseI is more appropriate for genomes poor in guanine and cytosine $(\mathrm{G}+\mathrm{C})$, HindIII/MseI is best for genomes with intermediate $\mathrm{G}+\mathrm{C}$ (40 to 50\%) content, and ApaI/TaqI is most suitable for genomes rich in $\mathrm{G}+\mathrm{C}$.

Joint analysis of all 3 marker types exhibited results similar to those obtained with AFLP markers alone, clearly demonstrating that the latter prevailed over the other markers in joint analysis. This finding agreed with those of a study by Laborda et al. (2005), in which diversity estimates based on AFLP exhibited poor correlation with those corresponding to SSR. Laborda et al. (2005) have observed that joint analysis (AFLP/SSR) was not the most efficient method for assessing variability across tropical accessions. Such evidence was confirmed by the high correlation (96\%) of similarity matrices between AFLP and joint analysis of markers.

Laborda (2003) has studied tropical maize lines using SSR and AFLP markers and claims that the discrepancy in the results may be due to differences in the evolution rate of each marker. For instance, Vigouroux et al. (2002) have cited an SSR mutation rate on the order of $10^{-3}$, whereas the rate for AFLP is $10^{-6}$. These differences in mutation rates may result in differing assessments of the genome when genotyping is carried out using SSR and AFLP markers. The lower genetic variability among landrace varieties expressed with AFLP compared to SSR markers might be supported by the discrepancy in mutation rates because the genetic similarity estimated by SSR was slightly lower compared with that of AFLP. Conversely, the amplitude of variation in diversity values was higher in SSR compared with that in AFLP markers. These results confirm the hypothesis that SSR exhibits a greater capability to explore diversity, reveals greater polymorphism, and thus samples higher genetic variability across accessions of maize landraces.

The dendrograms constructed using similarity data for each marker illustrated several discrepancies. Overall, the clustering analysis showed that the combination of landrace varieties exhibiting the highest index of genetic similarity in AFLP and joint analysis was Asteca (V6) with Carioca (V11); for SSR, Nutricional (V1) with Branco para Palha (V9), and for RAPD, Asteca (V6) with Caiano (V7). Clustering showed combinations of varieties that might maximize heterosis through artificial crossing in breeding programs. For instance, in the 
case of RAPD markers, landrace varieties from group A could be crossed with isolated varieties População Nonoai (V28), Crioulo Rosa (V34), and Crioulo 8 Carreiras (V31). Regarding SSR markers, the greatest heterosis might be expected from crossing group A and $\mathrm{H}$ (V25, V32, and V41) genotypes. The dendrograms generated for AFLP and joint analysis featured the same tree topology with slight alterations. Specifically, crossing schemes involving group A and the more distant isolated genotypes might allow for greater success in the production of genetic variability and thus might maximize the exploitation of heterosis and segregation.

The discrepancies in the dendrograms generated by the 3 marker types and joint analysis occurred mainly because each marker assesses different genomic regions. The varieties that clustered in the same group (A) in all 4 dendrograms were Nutricional (V1), Milho Grande (V2), Palha Roxa (V3), and Paiol (V4), thereby denoting high genetic similarity across these accessions independent of marker type. Comparison of the RAPD and SSR dendrograms revealed that a higher number of landraces belonged to the same group (A): Branco (V5), Asteca (V6), Caiano (V7), Branco para Palha (V9), Carioca (V11), Vinten (V13), Encantilado (V15), Amarelo Antigo (V17), and Crioulo 8 Carreiras (V18). By contrast, the AFLP dendrogram was notably similar to that resulting from joint analysis. Twelve varieties were included in group B of both dendrograms (V1, V11, V12, V13, V14, V15, V17, V18, V19, V20, V23, and V30), 2 in group C (V46 and V47), and only Caiano FE 121 (V37) in group E. Similarly, the same 11 landrace varieties remained isolated in the AFLP and joint analysis dendrograms (V39, V24, V25, V43, V31, V40, V8, V38, V42, V27, and V16). Landraces Branco (V16), Branco Dentado (V38), and Crioulo 8 Carreiras (V31) were the most divergent based on genetic similarity and clustering analyses.

With respect to collection sites, 2 dendrograms (RAPD and AFLP) exhibited a predominance of groups with genotypes exclusively from RS, followed by groups of genotypes exclusively from PR (AFLP) or both locations (AFLP and RAPD). With SSR markers, the groups comprising landraces from both locations prevailed (5), and only 3 included genotypes exclusively from RS. By contrast, in joint analysis, 3 groups contained varieties exclusively from RS, 2 exclusively from PR, and 2 from both locations. Group A in the RAPD and SSR dendrograms displayed an interesting feature: a predominance of landrace varieties from PR compared with those from RS (15:1 and 13:5, respectively). The presence of varieties from RS in this group may be due to varieties from PR having been previously introduced from RS during the historical period of colonization. Nevertheless, groups with varieties exclusively from PR may have formed as a result of both the regional fixation of alleles that differentiated during the geographical expansion of those varieties and their isolation by means of physical barriers hindering genetic flow between locations. In addition, the growing awareness of family farmers about avoiding the mixing of seeds likely contributed significantly to the predominant clustering of varieties as a function of collection site.

The stability of dendrograms is an important feature to consider in studies involving the clustering of genotypes according to genetic similarity/dissimilarity indices (Carvalho et al., 2004). Analysis of genetic diversity examining various tropical maize lines has demonstrated that 150 polymorphic fragments are sufficient to stabilize the clustering of corresponding lines (Lanza et al., 1997; Pejic et al., 1998). Bootstrap analyses performed by Barbosa et al. (2003) and Garcia et al. (2004) have shown that at least 262 (RAPD) and 232 (AFLP) but only 29 (SSR) polymorphic fragments are needed to stabilize the coefficient of variation at $10 \%$. The number of polymorphic fragments used in our analysis was 335 with RAPD, 762 
with AFLP, and 105 with SSR. These numbers were well above the number recommended to produce accurate information on the index of genetic similarity and promote stability in the clustering analysis of maize landrace varieties.

Although the index of genetic similarity was high in several pairs of combinations of landrace varieties, most of the varieties revealed high genetic diversity based on genotyping with all 3 marker types. These results have been confirmed when the agronomic characterization of these accessions is taken into account (Araújo and Nass, 2002). In addition, these varieties appear to be a positive source of genetic variability regarding characteristics of agronomic interest, such as tolerance to toxic aluminum, that have been poorly exploited in this germplasm to date (Coelho, 2011). In this sense, molecular genotyping with various markers and agronomic characterization of these landraces may allow mining for new genes of economic interest, reveal the most promising crossings to maximize heterosis and preserve a portion of this genetic variability that has been poorly exploited by crop breeding programs.

In conclusion, molecular analysis allowed the identification of high genetic variability in the germplasm of tropical maize landraces independent of marker type. RAPD and SSR markers exhibited higher average indices of polymorphism compared with those of AFLP, although the latter was more efficient in the production of polymorphic fragments. Landraces predominantly clustered as a function of the collection sites. In general, the dendrograms generated using RAPD and AFLP markers exhibited a predominance of groups constituted by varieties from RS, and with SSR markers, groups were composed of accessions from both locations. Groups of landraces exclusively from RS and PR supported the hypothesis of divergence among these groups that may be due to the fixation of regional adaptation alleles and the presence of physical barriers hindering genetic flow between these locations. However, the evolution time was insufficient to achieve complete separation of varieties into exclusive groups from RS and PR.

\section{ACKNOWLEDGMENTS}

Research supported by the Araucaria Foundation (protocol \#15520/2009), and the Brazilian Federal Agency for the Support and Evaluation of Graduate Education (Coordenação de Aperfeiçoamento de Pessoal de Nível Superior) for a Master's grant to D. Molin.

\section{REFERENCES}

Adeyemo O, Menkir A, Melaku G and Omidiji O (2011). Genetic diversity assessment and relationship among tropicalyellow endosperm maize inbred lines using SSR markers. Maydica 56: 1703-1709.

Araújo PM and Nass LL (2002). Caracterização e avaliação de populações de milho crioulo. Sci. Agric. 59: 589-593.

Barbosa AMM, Geraldi IO, Benchimol LL, Garcia AAF, et al. (2003). Relationship of intra- and interpopulation tropical maize single cross hybrid performance and genetic distances computed from AFLP and SSR markers. Euphytica 130: 87-99.

Bruel DC, Carpentieri-Pípolo V, Ruas CF, Gerage AC, et al. (2007). Assessment of genetic diversity in maize inbred lines using RAPD markers. Crop Breed. Appl. Biotechnol. 7: 173-178.

Caixeta ET, Oliveira ACB, Brito GG and Sakiyama N (2009). Tipos de marcadores moleculares. In: Marcadores Moleculares. 2nd ed (Borém A and Caixeta ET, eds.). Embrapa Café, Viçosa, 54-66.

Carvalho VP, Ruas CF, Ferreira JM, Moreira RMP, et al. (2004). Genetic diversity among maize (Zea mays L.) landraces assessed by RAPD markers. Genet. Mol. Biol. 27: 228-236.

Coelho CJ (2011). Avaliação da Tolerância ao Alumínio Através da Solução Mínima em Diferentes Germoplasmas de Milho. Master's thesis, Universidade Estadual de Ponta Grossa, Ponta Grossa. 
Creste S, Tulmann Neto A and Figueira A (2001). Detection of simple sequence repeat polymorphisms in denaturing polyacrylamide sequencing gels by silver staining. Plant Mol. Biol. Rep. 19: 299-306.

Cruz CD (2006). Programa Genes: Biometria. Editora UFV, Viçosa.

Eschholz TW, Peter R, Stamp P and Hund A (2008). Genetic diversity of Swiss maize (Zea mays L. ssp. mays) assessed with individuals and bulks on agarose gels. Genet. Resour. Crop Evol. 55: 971-983.

Garcia AAF, Benchimol LL, Barbosa AMM, Geraldi IO, et al. (2004). Comparison of RAPD, RFLP, AFLP and SSR markers for diversity studies in tropical maize inbred lines. Genet. Mol. Biol. 27: 579-588.

Gerber S, Mariette S, Streiff R, Bodenes C, et al. (2000). Comparison of microsatellites and amplified fragment length polymorphism markers for parentage analysis. Mol. Ecol. 9: 1037-1048.

Hartings H, Berardo N, Mazzinelli GF, Valoti P, et al. (2008). Assessment of genetic diversity and relationships among maize (Zea mays L.) Italian landraces by morphological traits and AFLP profiling. Theor. Appl. Genet. 117: 831-842.

Hoisington D, Khairallah M and González de León D (1994). Laboratory Protocols: CIMMYT Applied Molecular Genetics Laboratory. 2nd edn. CIMMYT, Mexico.

Janssen P, Coopman R, Huys G, Swings J, et al. (1996). Evaluation of the DNA fingerprinting method AFLP as an new tool in bacterial taxonomy. Microbiology 142 (Pt 7): 1881-1893.

Kostova A, Todorovska E, Christov N, Sevov V, et al. (2006). Molecular characterization of Bulgarian maize germoplasm collection via SSR markers. Biotechnol. Biotec. Eq. 20: 29-36.

Laborda PR (2003). Diversidade Genética entre Linhagens de Milho Tropical: Estudo com Base em Marcadores Moleculares. Master's thesis, Universidade Estadual de Campinas, Campinas.

Laborda PR, Oliveira KM, Garcia AA, Paterniani ME, et al. (2005). Tropical maize germplasm: what can we say about its genetic diversity in the light of molecular markers? Theor. Appl. Genet. 111: 1288-1299.

Lanza LLB, Souza Jr CL, Ottoboni LMM, Vieira MLC, et al. (1997). Genetic distance of inbred lines and prediction of maize single-cross performance using RAPD markers. Theor. Appl. Genet. 94: 1023-1030.

Legesse BW, Myburg AA, Pixley KV, Twumasi-Afriyie S, et al. (2008). Relationship between hybrid performance and AFLP based genetic distance in highland maize inbred lines. Euphytica 162: 313-323.

Mantel N (1967). The detection of disease clustering and a generalized regression approach. Cancer Res. 27: 209-220.

Moeller DA and Schaal BA (1999). Genetic relationships among Native American maize accessions of the Great Plains assessed by RAPDs. Theor. Appl. Genet. 99: 1061-1067.

Ogliari JB, Boscariol RL and Camargo LEA (2000). Optimization of PCR amplification of maize microsatellite loci. Genet. Mol. Biol. 23: 395-398.

Paterniani E, Nass LL and Santos MX (2000). O Valor dos Recursos Genéticos de Milho para o Brasil: Uma Abordagem Histórica da Utilização do Germoplasma. In: Uma História Brasileira do Milho: O Valor dos Recursos Genéticos (Udry CW and Duarte W, eds.). Paralelo, Brasília: 11-14.

Pejic I, Ajmone-Marsan P, Morgante M, Kozumplick V, et al. (1998). Comparative analysis of genetic similarity among maize inbred lines detected by RFLPs, RAPDs, and AFLPs. Theor. Appl. Genet. 97: 1248-1255.

Pollack LM (2003). The history and success of the public-private project on germplasm enhancement of maize (GEM). Adv. Agron. 78: 45-87.

Rinaldi DA, Pípolo VC, Gerage AC, Ruas CF, et al. (2007). Correlação entre heterose e divergência genética estimadas por cruzamentos dialélicos e marcadores moleculares RAPD em populações de milho-pipoca. Bragantia 66: 183-192.

Rohlf FJ (1992). NTSYS-pc: Numerical Taxonomy and Multivariate Analysis System. Version 2.1. Exeter software, Setauket.

Saiki RK, Gelfand DH, Stoffel S, Scharf SJ, et al. (1988). Primer-directed enzymatic amplification of DNA with a thermostable DNA polymerase. Science 239: 487-491.

Senior ML, Chin ECL, Lee M, Smith JSC, et al. (1996). Simple sequence repeat markers developed from maize sequences found in the GENBANK database: map construction. Crop Sci. 36: 1676-1683.

Tautz D (1989). Hypervariability of simple sequences as a general source for polymorphic DNA markers. Nucleic Acids Res. 17: 6463-6471.

Terra TF, Wiethölter P, Almeida CC, Silva SDA, et al. (2011). Genetic variability in maize and teosinte populations estimated by microsatellites markers. Ciência Rural 41: 205-211.

Vigouroux Y, Jaqueth JS, Matsuoka Y, Smith OS, et al. (2002). Rate and pattern of mutation at microsatellite loci in maize. Mol. Biol. Evol. 19: 1251-1260.

Vos P, Hogers R, Bleeker M, Reijans M, et al. (1995). AFLP: a new technique for DNA fingerprinting. Nucleic Acids Res. 23: 4407-4414.

Vuylsteke M, Mank R, Antonise R, Bastiaans E, et al. (1999). Two high-density AFLP ${ }^{\circledR}$ linkage maps of Zea mays L.: analysis of distribution of AFLP markers. Theor. Appl. Genet. 99: 921-935.

Williams JG, Kubelik AR, Livak KJ, Rafalski JA, et al. (1990). DNA polymorphisms amplified by arbitrary primers are 
useful as genetic markers. Nucleic Acids Res. 18: 6531-6535.

Xiang K, Yang KC, Pan GT, Reid LM, et al. (2010). Genetic diversity and classification of maize landraces from China's Sichuan basin based on agronomic traits, quality traits, combining ability and SSR markers. Maydica 55: 85-93.

Yang X, Xu Y, Shah T, Li H, et al. (2011). Comparison of SSRs and SNPs in assessment of genetic relatedness in maize. Genetica 139: 1045-1054.

Yao Q, Yang K, Pan G and Rong T (2007). Genetic diversity of maize (Zea mays L.) landraces from southwest China based on SSR data. J. Genet. Genomics 34: 851-859.

Zabeau M and Vos P (1993). Selective Restriction Fragment Amplification: A General Method for DNA Fingerprinting. European Patent Office, Publication \#0534858-A1, Bulletin 93/13, Paris. 